\title{
On the inconstancy of the potential required for a spark
}

\section{G. Jaumann}

To cite this article: G. Jaumann (1895) On the inconstancy of the potential required for a spark, Philosophical Magazine Series 5, 40:245, 396-396, DOI: $10.1080 / 14786449508620785$

To link to this article: http://dx.doi.org/10.1080/14786449508620785

Published online: 08 May 2009.

Submit your article to this journal ¿

Q View related articles $\sqsubset$ 
A small light mirror is fastened with wax to the ribrating body in the usual way, and a telescope is sighted at a distance of about two metres. Between the telescope and the mirror is fixed near the latter a thin plane glass, silvered by means of Bïtturer's sulution, making an angle of $45^{\circ}$ with the rertical. This must refluct more light than it transmits.

A watch is placed on a table below the mirror so that its imase reflected from the silvered surface is distinctly visible in the field of view of the telescope. The watch must be brightly lighted by a lamp, and another lamp so placed near the telescope that its rays passing through the transparent conting are reflected by the small mirror into the telescope. On looking through the telescope atter the body has been made to oscillate, we see the second-hand strongly magnified, while at each oscillation the small vibrating mirror gives a short flash in the field of view. The image of the secondhand moves in the opposite direction to the hand itself. By following the motion of the hand it is easp to accurately cletermine the time of the fiash to a quarter of a second. If the oscillations are rapid, it is of course more convenient only to observe the time of every fifth or tenth oscillation. After a few observations we linow when the following is to be expected, and by fixiug the eve on the division of the dial where the second-hand will be at the moment of the flash, it is possible to determine the time to within a quarter of a second. We soon get accustomed to the backward motion of the index, and the reading is as easy as the ordinary one.

Instead of the semitransparent silver mirror an ordinary opaque plane mirror mas be used (metal of comrse is best), if it is so arranged that the mirror on the oscillating body is visible just above or below its edge.-W Wedemann's Anmalen, No.9, 1895.

ON THE INCONSTANOY OF THE POTENTIAL REQUIRED FOR A SPARK. BY G. JAUMANN.

The author summarizes as follows the results of his inrestigation:-

I. Sparks alter the path through which they pass; strong ones in an unfavourable sense, and weak ones often in a farourable sense. The path spontaneously recovers from this after-action in the course of some hours.

II. By avoiding the smallest variations of force very high potentials may be obtained.

III. When the conditions for a discharge are not quite satisfied, the discharge takes place after a delay of a few seconds to several minutes. During this retardation there is a preliminary process of discharge which itsell is no real discharge.

IV. During this retardation the excitiug infuence of variations of force can be demonstrated in au incontestable manner.

V. A moderate variation of force does not produce the spark at once, but only after $0 \cdot 1-5$ seconds. It only accelerates the prelivinary process and shortens therefore the retardation.-Wiedemaun's Annalen, No. 8, 1895. 